\title{
LETTERS
}

\section{Advance Care Planning Safeguards}

\author{
Sangeeta C. Ahluwalia, PhD, MPH' and Howard S. Gordon, MD \\ 'West Los Angeles Veterans Affairs Medical Center, University of California at Los Angeles, CA, USA; ${ }^{2}$ Jesse Brown Veterans Affairs Medical \\ Center, University of Illinois at Chicago, IL, USA.
}

$\mathrm{J}$ Gen Intern Med 27(11):1404

DOI: $10.1007 / \mathrm{s} 11606-012-2190-6$

(C) Society of General Internal Medicine 2012

To the Editors:-We read with interest the recent article by Dr. Billings. ${ }^{1}$ In the article, Dr. Billings defines the goal of advance care planning as promoting the autonomy of decisionally incapacitated patients in decision-making about life-sustaining treatment, and cites public fears about restricting life-sustaining treatment as evidence for implementing certain safeguards in advance care planning, such as erring on the side of preserving life when advance directives are unclear.

However, a broader conceptualization of advance care planning as the process by which patients can receive preference-concordant care over the course of a serious illness, ${ }^{2}$ including but not limited to life-sustaining treatment, makes advance care planning relevant to more patients. We believe that this frame for advance care planning may shift public and political attention away from fears about restricting treatment, and toward increasing access to patient-centered care overall.

Defining the goal of advance care planning as providing preference-concordant care through the trajectory of an illness requires a different set of safeguards, including 1) having early and repeated patient-provider discussions about values of care within the context of the patient's illness trajectory; 2) identifying ways to usefully translate broad values into specific preferences at the time of decision-making; 3 ) encouraging a re-evaluation of documented preferences with changing clinical and personal circumstances; and 4) implementing a system-wide transportable and flexible method of preference documentation that more adequately reflects patients' values than traditional advance directives.

A first step in achieving this vision of advance care planning includes helping patients clarify and articulate their underlying values for care and thereby identifying specific treatment preferences. Clinicians might facilitate this goal with multiple, brief, discussions about patients' reflections and feelings regarding health states, as personally experienced or observed. ${ }^{3}$

While the relevance of advance care planning might be most apparent when decisions about life-sustaining treatment need to be made, we suggest a focus on the process of consideration, evaluation and discussion of values and preferences rather than towards the life or death decision itself. Such a shift within the medical community in thinking and practice, we believe, will have the effect of positively shifting public opinion about advance care planning and would support patient-centered care in serious illness.

Corresponding Author: Sangeeta C. Ahluwalia, $\mathrm{PhD}, \mathrm{MPH}$; West Los Angeles Veterans Affairs Medical Center, University of California at Los Angeles, 11301 Wilshire Blvd., 111-G, Los Angeles, CA 90073, USA (e-mail: sangeeta.ahluwalia@va.gov).

\section{REFERENCES}

1. Billings JA. The need for safeguards in advance care planning. J Gen Intern Med. 2012;27(5):595-600. doi:10.1007/s11606-011-1976-2.

2. Gillick MR. A broader role for advance medical planning. Ann Intern Med. 1995;123(8):621-4.

3. Sudore RL, Fried TR. Redefining the "planning" in advance care planning: preparing for end-of-life decision making. Ann Intern Med. 153(4):256-61. 